\title{
Trabalho infantil e ideologia: contribuição ao estudo da crença indiscriminada na dignidade do trabalho
}

\author{
Herculano Ricardo Campos \\ Alex Reinecke de Alverga \\ Universidade Federal do Rio Grande do Norte
}

\begin{abstract}
Resumo
No Brasil, a maioria das ações de combate ao trabalho infantil busca assegurar às famílias das vítimas apoio financeiro para compensar a renda até então auferida por elas. Contudo, pesquisas constatam que, aliada à permanência de grande número de crianças no trabalho, observa-se a crença das famílias, das próprias crianças, dos empregadores e até mesmo de muitos agentes encarregados do combate a esse tipo de trabalho, de que ele só trará benefícios para as crianças. Neste sentido, avaliase, as ações de combate encontram-se comprometidas em face de aspectos subjetivos afirmativos do trabalho, de modo que seu sucesso parece condicionado ao desvelamento desses aspectos. O presente estudo oferece dados que permitem uma maior compreensão do processo social e histórico por meio do qual a ideologia do trabalho como educador, dignificante, se estabeleceu nas mentalidades do povo brasileiro e orientou as políticas públicas voltadas para a criança.
\end{abstract}

Palavras-chave: Trabalho, Trabalho infantil, Ideologia, Políticas públicas.

\begin{abstract}
Child work and ideology: Contribution to the study about the indiscriminated belief on the dignity of work. In Brazil, most of the actions that fight child labor offers financial support to the victim's families as a supplement to their lost income. Nevertheless, previous studies have shown that many children remain in their work lurked to a belief by the children themselves, their families, their employers and even technicians who are responsible for the erradication of child labor, that this kind of work will bring benefits to the children. Accordingly, the success of the actions intended to reduce child labor should be connected and conditioned to better comprehension of these aspects. This study contributes to this understanding, presenting issues about the social and historical processes by which the ideology of labor as educative and dignifying was settled down in the mentality of Brazilian people and has oriented the public policies related to childhood.
\end{abstract}

Key words: Work, Child work, Ideology, Public policies

\section{Apresentação}

$\mathrm{M}$ esmo em face do grandioso desenvolvimento tecnológico possibilitado pela eletrônica e informática, observado no mundo contemporâneo, uma verdadeira chaga social surgida desde o século XVII, a exploração de mão-de-obra infantil em atividades produtivas, persiste em se fazer presente. Dada como erradicada no início do século XX, nos países de capitalismo central como a Inglaterra e Estados Unidos, desde o se- gundo quartel desse mesmo século vários estudos e instituições denunciam a reincidência da situação, em que pesem algumas mudanças de feições. Nos países em desenvolvimento, por um lado, em decorrência das ações capitaneadas pela Organização Internacional do Trabalho - OIT -, no contexto das quais aponta-se para a erradicação do trabalho infantil, as estatísticas oficiais revelam diminuição do número de crianças no trabalho. Contudo, por outro lado, muitos estudos têm dado conta das renovadas formas de inserção 
das crianças no trabalho, não apontadas nas pesquisas levadas a cabo pelos governos, de modo que se avalia de maneira geral crescente o número de crianças trabalhando no setor produtivo e de famílias que requerem o trabalho das crianças para sobreviverem.

Como referido, a configuração de uma parcela significativa da força de trabalho infantil é devida a necessidades geradas no seio familiar, decorrentes das insuficientes condições de sobrevivência. Porém, observa-se que tanto as famílias quanto outros setores da sociedade atrelam às justificativas de teor econômico razões de caráter subjetivo para estimular, encorajar as crianças a, cedo, ingressarem em alguma atividade produtiva. Ao tratar-se de certa parcela dos adolescentes, então, observa-se a defesa intransigente do direito e daimportância do trabalho produtivo, na maior parte das vezes em detrimento de atividades esportivas, estudantis etc., ainda que o trabalho desenvolvido represente sério dano físico ou mental.

Associado à realidade social e econômica, o apoio familiar à inserção precoce no trabalho produtivo subsiste a despeito da legislação que coíbe a contratação e o exercício desse tipo de atividade por crianças, e a tantos programas de atendimento voltados para essa população. Toda a proibição e evidência das consequiências nefastas do trabalho precoce não têm sido suficientes para fazer estancar o crescimento dos índices das novas vítimas flagradas no trabalho doméstico, na agricultura, nas atividades terceirizadas e domiciliaresetc.

Neste sentido, o presente estudo parte da compreensão de que a perspectiva de erradicação do trabalho infantil requer, da parte dos responsáveis pela formulação e implementação das propostas nessa direção, considerar a necessidade de combater os aspectos subjetivos dos sujeitos envolvidos, no sentido das crenças pessoais de patrões, famílias e crianças sobre o trabalho.

Tendo em vista a inserção precoce no trabalho produtivo, as deficitárias condições de vida têm recebido a parceria e o estímulo fundamentais de uma ideologia reificadora do trabalho, a tal ponto que um dos mais famosos ditos populares da nossa cultura ocidental, de que "o trabalho dignifica o homem", muitas vezes assume um caráter inquestionável, possibilitando que o trabalho, até mesmo quando exercido de forma indigna, seja visto como um valor supremo, como formador do espírito, educador. Por que o trabalho é considerado desta maneira?

De acordo com Mészáros (1995), situando o debate no contexto da heurística marxista, essa submissão dos indivíduos ao trabalho não passaria de um epifenômeno da subsunção do trabalho ao capital. Max Weber (1989, p. 19), por outro lado, afirma que "os líderes do mundo dos negócios e proprietários do capital, assim como dos níveis mais altos da mão-de-obra qualificada" são "preponderantemente protestantes", daí inferindo que é no "caráter intrínseco permanente de suas crenças religiosas" que deve ser buscada a explicação para sua maior - pelo menos quando comparados aos católicos - "tendência específica para o racionalismo econômico" (p. 23).

Na tentativa de identificar como se configurou essa compreensão do trabalho em solo brasileiro, contudo, encontrase fortes indícios de que sofreu influência de certas tradições culturais já presentes na época da formação do Estado Português, ainda no século XIV, sendo recontextualizadas, ressaltadas e aprofundadas pela perspectiva capitalista configurada somente alguns séculos depois. Ou seja, enquanto a divisão do trabalho operada na estrutura feudal portuguesa requer uma relativização das interpretações marxistas, o espírito empreendedor observado naquele povo católico solicita ponderações às interpretações weberianas.

Assim, a hipótese deste estudo é que a concepção sobre o trabalho sobrexistente no Brasil, identificada nas políticas voltadas para a criança e o adolescente, derivou de duas concepções cujas justificações, no âmbito teológico, apresentavam-se opostas e inconciliáveis, mas que, por outro lado, identificavam-se perfeitamente no aspecto social. Inicialmente, derivou da visão classista que atribuía ao trabalho manual um status de indignidade, e por isso não pertinente aos nobres, presente desde os primórdios da cultura ibérica; e posteriormente, recebe o impulso definitivo de uma ética do trabalho que é originária da moral puritana, hegemônica na Inglaterra no século XVIII, a qual traduz-se socialmente também como um instrumento de divisão e opressão de classes, na medida em que destina aos desvalidos da sociedade o trabalho manual, mais pesado e menos respeitado que o intelectual.

Antes de mais nada, esclareça-se em que medida as justificações de portugueses e ingleses, no campo teológico, não eram assimiláveis entre si.

\section{Contradições teológicas}

Para portugueses e espanhóis, a ação sobre o universo material, o mundo exterior, por pressupor submissão a leis estranhas ao indivíduo, ao contrário do respeito a valores como "inteireza", "ser", "gravidade", "proceder sisudo", prejudica e avilta a glória de Deus. "O trabalho manual e mecânico visa a um fim exterior ao homem e pretende conseguir a perfeição de uma obra distinta dele" (Holanda, 1984, p. 10). Por outro lado, para os calvinistas ingleses, toda humanidade sofria de uma inata pecaminosidade, fazendo-se necessário frear e controlar o espírito dos jovens, inculcando-lhes desde muito cedo aqueles valores julgados corretos para uma boa sociedade, os mesmos desejados pela indústria, como diligência e aplicação (Horn, 1994). Logo, enquanto a primeira perspectiva remetia ao ócio e à contem- 
plação, a outra fundava uma ética do trabalho a qual, nas nações ibéricas, só encontra guarida muito recentemente, e assim mesmo sob muitas ressalvas.

Para os ibéricos, a idéia de nobreza estava mais articulada com as riquezas amealhadas por cada indivíduo, com os títulos decorrentes dos altos feitos, e menos com os laços de sangue, a descendência. Em decorrência, ali floresceu a ênfase no mérito pessoal, no livre arbítrio, que por remeter ao espírito de aventura, de ocasião, punha-se no pólo oposto à perspectiva de associação inferida das doutrinas protestantes, inclusive no que dizia respeito à capacidade de organização social. Na Inglaterra, a partir de quando os puritanos davam o tom da ideologia hegemônica, a crença em um espírito humano naturalmente pecaminoso levava à proposição de princípios pedagógicos caros às organizações industriais, por acreditarem que a disciplina neles contida seria necessária para regular, controlar, frear o espírito voluntarioso dos jovens. Por outro lado, essa moral do trabalho, ao invés da dispersão observada nos outros países, possibilitava maior propensão à busca de coesão social e organização racional dos homens, constituindo uma possível explicação para o sucesso da Inglaterra enquanto potência mundial do capitalismo nascente.

Em segundo lugar, justifique-se a afirmação de que, embora inconciliáveis no plano teológico, ambas concepções identificavam-se no âmbito social.

\section{Trabalho e sociedade: convergências}

As implicações semelhantes sobre o tecido social decorrem da distinção verificada nas duas concepções entre trabalho manual e intelectual, não representando o exercício deste último um desmerecimento, um motivo de descrédito, como era considerada a prática do trabalho manual. A visão portuguesa sobre o trabalho encontra raízes nas lutas intestinas observadas durante a formação do Estado Português, ainda durante o século XIV, quando o desenvolvimento da burguesia comercial não foi suficiente para romper o jugo exercido pela coroa e pelos fidalgos a ela filiados, mantendo-se o comércio enquanto delegação "do supremo mercador, o rei em pessoa" (Faoro, 2000, p. 60). Na medida em que a burguesia se acomodava ao "estado-maior dirigente" (p. 60) e à estratificação social então vigente, por um lado via formar-se e ganhar poder no paço real uma burocracia constituída de jovens letrados, provenientes das famílias burguesas em condições de oferecer educação universitária aos seus filhos, e, por outro lado, justamente por causa da nova ênfase no trabalho intelectual, sentia sobre si os efeitos do "descrédito ao negócio e ao trabalho manual, essenciais ao desenvolvimento da nação, em favor de valores que consagraram a ociosidade letrada" (p. 60). Contraditoriamente, portanto, o Estado português se alimentava do trabalho da mesma classe que aviltava e desprezava.
A clara distinção entre as formas de trabalho, empreendida pelos portugueses desde alguns séculos antes do advento do capitalismo, possuía caráter evidentemente segregacionista e constituía-se em meio privilegiado de obtenção de favores. Observe-se, contudo, que estudiosos da história antiga de Portugal, como Gil Vicente e Alberto Sampaio, citados por Holanda (1984, p. 7), afirmam que a nobreza não visava constituir-se uma aristocracia fechada, ou seja, “[...] havia homens da linhagem dos Filhos d'algo em todas as profissões, desde os oficiais industriais, até os arrendatários de bens rústicos", do que parece ser possível inferir a democratização das possibilidades de ascensão social. Porém, o limite de tal perspectiva, assim como o veio discriminatório nela embutido, aparece quando também se lê nos mesmos autores citados que aos que almejavam a nobreza, "unicamente lhes são negadas as honras enquanto viverem de trabalho mecânico". Logo, para os portugueses, e espanhóis, a correria desesperada pelo pão de cada dia de forma alguma era sinônimo de nobreza, de qualidade de vida, importando-lhes mais a contemplação e o amor, mais o ócio que a atividade produtora, o negócio.

Na Inglaterra, porém, a situação tinha algumas nuanças interessantes. A concepção puritana torna-se hegemônica apenas a partir dos séculos XVII e XVIII; ainda assim, sua influência sobre as atitudes a serem tomadas com as crianças, que envolvia diretamente a concepção sobre o trabalho, sofreu a oposição de outra visão, assente nas idéias de JeanJacques Rosseau e dos poetas românticos ingleses, como é exemplo W. Wordsworth.

Tomando por base o estudo de Holanda (1984), observa-se que o inglês de antes da era vitoriana, "o inglês típico", possuía características bastante diferenciadas daqueles que viriam a sucedê-lo, não possuindo o espírito empreendedor e poupador desses. Ao contrário, tendia "para a indolência e para a prodigalidade", a exemplo dos ibéricos também sendo um amante da boa vida. Thomas Mun, citado por Holanda (p. 15), "censurava nos seus compatriotas a imprevidência, o gosto da dissipação inútil, o amor desregrado aos prazeres e ao luxo, a ociosidade impudica [...]". Na mesma perspectiva, afirmava William Ralph Inge que "a indolência é vício que partilhamos com os naturais de algumas terras quentes, mas não com qualquer outro povo do Norte da Europa" (Holanda, 1984, p. 15). A hegemonia puritana, observada a partir do século XVII, representou a vitória dos moralistas, no sentido de dotar a Inglaterra de um instrumento capaz de superar a inferioridade demonstrada frente outras nações, suas competidoras.

No século XVII observou-se o ocaso do feudalismo e o redimensionamento da estrutura produtiva, em direção ao capitalismo. Naquele contexto, igual transformação ocorreu na forma de se entender a família., de modo que, a partir de 
então, atenção especial foi destinada ao espaço privado, ao invés da promiscuidade mundana antes observada, na qual as crianças incluíam-se de forma indiferenciada, daí brotando o sentimento moderno de infância. A nova família toma para si um importante aspecto da formação do "novo homem", qual seja o ensino cotidiano dos afazeres domésticos e dos ofícios, emprestando ao trabalho o sentido primordial de educativo, formador (Ariès, 1978; Patto, 2000).

A ética do trabalho, contudo, a despeito do fundamento religioso, também se prestava à discriminação entre as classes, na medida em que a burguesia comercial inglesa, em ascensão, destinava aos seus filhos o trabalho mental, a "cultura da mente", restando aos membros das classes desprivilegiadas o ingresso prematuro no mundo do trabalho fabril, agrícola, artesanal etc. Segundo Horn (1994), uma implicação social da articulação entre aquela compreensão e esse proceder social foi a legitimação do emprego de crianças em diversos setores produtivos, como os serviços domésticos, visto acreditar-se que, assim, se emprestaria a dignidade a que o espírito almejava.

Nesse caso, de maneira geral, a procura dos capitalistas pelo lucro fácil, a miséria das famílias que abandonavam seus filhos nos orfanatos ou os alugavam para os donos de fábricas e a ideologia religiosa que possibilitava a todos se valerem das crianças, sem culpa e sob o manto da formação moral, foram os fatores que se integraram no sentido de fazer convergir para a indústria capitalista inglesa milhares de braços infantis.

Qualé, portanto, a ideologia do trabalho que anima as políticas voltadas para a criança, no Brasil?

\section{Trabalho e sociedade no Brasil}

No mesmo estudo em que efetua uma análise do conceito de infância que subjaz às políticas públicas brasileiras voltadas para esse segmento da população, Sonia Kramer (1982) procede a um retrospecto da evolução do conceito, identificando, a partir do século XVI, dois "sentimentos de infância", ou seja, duas maneiras particulares de expressão da consciência a respeito das diferenças entre crianças e adultos: a "paparicação" e a "moralização".

Muito embora o primeiro remeta à atitude de preservar a criança "da corrupção do meio, mantendo sua inocência", e o outro vise "fortalecê-la, desenvolvendo seu caráter e sua razão", afirma a autora que tais atitudes "não se opõem, [antes constituindo] os elementos básicos que fundamentam o conceito de criança como essência ou natureza, que persiste até hoje" (p.18). Neste sentido, ao mesmo tempo em que se configura uma denúncia do "ideal abstrato de criança" decorrente de tais sentimentos, seu estudo busca oferecer as bases para uma compreensão da criança, definida como um sujeito social e histórico.

Como referido anteriormente, foi justamente a partir dos séculos XVI e XVII que se observou a configuração de um conceito moderno de infância, intimamente articulado às transformações que se procediam na estrutura produtiva. Logo, como indicado por Horn (1994), ainda que a conformação desses sentimentos de infância também tenha sofrido influência da filosofia francesa, na figura de Jean-Jacques Rousseau, o estado de coisas desencadeado pelas mudanças econômicas e culturais na Inglaterra definiu a concepção hegemônica a ser transportada para o mundo, junto com o capitalismo e o sentimento de moralização das crianças.

Foi em face de tal contexto que a colonização portuguesa que se efetivava no Brasil observou o crescimento do domínio inglês sobre o comércio mundial, e a conseqüente vitória da ética protestante do trabalho, do empreendimento. Dessa maneira, no nosso país, a concepção vinda de Portugal, de que o trabalho manual era ignominioso, e assim indigno de ser exercido pelos membros das classes superiores, os nobres, facilmente articulou-se com as concepções classistas puritanas, que não obstante defenderem o trabalho das crianças, reservava as atividades intelectuais para seus filhos e as manuais para os das famílias menos privilegiadas na escala social.

Na sociedade colonialista e escravista brasileira, contudo, de acordo com Foot e Leonardi (1982), "a noção de indignidade do trabalho estava incorporada à atitude dos homens livres, mesmo à dos pobres. Certos artesãos livres chegavam a alugar um escravo para que este lhes carregasse $o$ martelo ou a talhadeira, quando transitavam pelas ruas" ( $\mathrm{p}$. 42). Ou seja, ainda que o caráter escravista da nossa colonização efetivasse a divisão do trabalho entre homens livres e escravos, tal não invalida o raciocínio de que ela traduzia um certo tipo de relação entre as classes na medida em que, com base na compreensão de Saes (1985), o escravo rural e o grande fazendeiro representavam as classes fundamentais e antagônicas naquela formação social.

Logo, da mesma forma paradoxal com que se prestava aos interesses do Estado Português, a noção de indignidade do trabalho passou a servir de instrumento de poder entre as classes também no Brasil, na medida em que o mesmo trabalho era receitado como o remédio para certos males da sociedade, ou seja, destinado a grupos específicos no espectro social.

\section{Trabalho infantil e legislação}

Ainda que a legalização desta perspectiva só se fizesse visível pela primeira vez em 1854, quando o Regulamento da Instrução Primária e Secundária do Município Neutro defendeu a criação de entidades profissionalizantes para "os meninos pobres e indigentes - a partir dos 12 anos - que vagavam pelas ruas", já por volta de 1840 , como indicado por Dulles (1977) e Foot e Leonardi (1982), muitas crianças eram empregadas nas indústrias nascentes.

Geralmente alugadas em instituições de caridade e asilos de órfãos, muitas dessas crianças não tinham mais de 10 
anos, havendo mesmo inúmeros casos de meninos e meninas de 5 ou 6 anos trabalhando 12 horas diárias, na indústria têxtil. Portanto, o Decreto de 1854 apenas oficializa o quadro em que se encontravam as crianças filhas da pobreza, para quem o trabalho apresentava-se como medida preventiva e remediadora dos males causados pela indigência social. Como referido acima, enquanto para eles a "indignidade" do trabalho manual era não só aceitável como recomendável, para os membros das classes dominantes o trabalho representava uma ignomínia, motivo de vergonha e expressão de submissão.

Muito embora desde 1830 a preocupação com a criança torne-se objeto de teses acadêmicas na Academia Imperial de Medicina do Rio de Janeiro, a discussão sobre o trabalho infantil não encontra espaço, em face do entendimento geral sobre a sua necessidade. Na compreensão de Irma Rizzini (1997), "Tenta-se apenas regulamentá-lo, evitandose os excessos, e tornar a criança mais apta a exercê-lo, através da criação de institutos e escolas profissionais" (p. 61).

A ideologia do trabalho como "elemento educativo, formador e reabilitador", que justificava sua prescrição como alternativa para "a vagabundagem", ajuda a explicar porque o Decreto n. 1.313, de 17 de janeiro de 1891, que "estabelecia providências para regularizar o trabalho dos menores empregados nas fábricas da Capital Federal", nunca foi cumprido. De acordo com Rizzini et al. (1995), "Deputados e senadores debatiam uma variedade de tópicos vinculados a leis em tramitação, mas estranhamente, a questão do trabalho infantil não parecia causar controvérsia" (p. 8-9).

\section{Trabalho infantil e educação}

A criação de escolas industriais ou instituições educacionais similares, em decorrência da crença de que a indolência é a principal fonte do mal e a indústria a principal virtude alcança, no Brasil, desde o início do século XX, o mesmo sucesso observado na Inglaterra nas últimas décadas do século XVIII, com as Sunday schools. No nosso país, algumas iniciativas neste sentido já se faziam observar no final do século XIX, como a criação, em 1874, do Instituto D. Ana Rosa e a transformação do antigo Seminário de Meninos no Instituto de Educandos Artífices; e, em 1882, com a transformação da Sociedade Propagadora da Instrução Popular no Liceu de Artes e Ofícios.

Contudo, foi a partir do início do século XX que essa perspectiva se mostrou mais sólida. De acordo com Faleiros (1995), "Em 1910 haviam sido instaladas 19 escolas [de Aprendizes e Artífices do Ministério da Agricultura, Indústria e Comércio] em todo o país com 1.248 alunos, e em 1923 é criada a Inspetoria do Ensino Profissional Técnico" (p. 64). Posteriormente, em 1939, "havia 7.000 alunos nos estabelecimentos de ensino profissional e técnico". Em 1942 é criado o Serviço Nacional de Aprendizagem Industrial
(SENAI) e, em 1946, o Serviço Nacional de Aprendizagem Comercial (SENAC), ambos em parceria com a iniciativa privada.

\section{Criança, trabalho e controle social}

No Brasil, um sentimento de infância, qual seja o entendimento da criança como ser que requer o fortalecimento do caráter, da razão, sentimento este acorde com as transformações no modo de produção, primeiramente ocorridas na Inglaterra, tanto serviu para encobrir a necessidade de fomentar o livre trabalho infantil quanto as estratégias de busca de controle social da juventude. O controle foi viabilizado a partir do artifício jurídico que efetuava a distinção entre criança e menor, representando este último o objeto das políticas públicas de contenção, de controle do Estado.

De acordo com o levantamento empreendido por Irma Rizzini (1993) nos escritos jurídicos do período compreendido entre 1923 e 1941, o "menor" era entendido como aquele que, além de “... uma infinidade de características negativas [da família], tem a sua conduta marcada pela amoralidade e pela falta de decoro, sua linguagem é de baixo calão, sua aparência é descuidada, tem muitas doenças e pouca instrução, trabalha nas ruas para sobreviver e anda em bandos com companhias suspeitas" (p. 96). Em outras palavras, denunciando o sentido ideológico e segregacionista de uma tal definição, ele seria o antônimo da criança bem cuidada, filha de família burguesa dotada dos suficientes recursos para lhe garantir o acesso a uma boa escola, boas roupas, médicos etc.

A compreensão da articulação entre criança, trabalho e controle social deve ter claro o caráter de classe do trabalho e a certeza de que aos interesses dos capitalistas opõem-se aos dos trabalhadores. Na medida em que se opera no seio da sociedade uma divisão entre trabalho manual e intelectual, de modo que a classes diferentes destina-se tipo também diferente de trabalho, parece certo que uma das condições para a reprodução do capital radica, justamente, no exercício do controle sobre os futuros trabalhadores manuais - os menores, filhos da pobreza.

É neste sentido que o embate travado entre os empresários e os trabalhadores, tendo como objeto o trabalho infantil, deve ser entendido na perspectiva da luta entre classes. O trabalho das crianças sempre representou uma preocupação para o movimento organizado dos trabalhadores brasileiros que, pelo menos desde 1912, inseriu nas suas pautas de reivindicações a diminuição da jornada para os menores de 18 anos e a eliminação do trabalho dos menores de 14 anos de idade.

Por exemplo, quando, durante o Quarto Congresso Operário Brasileiro, realizado no Rio de Janeiro, entre os dias 7 e 15 de novembro de 1912, cento e oitenta e sete delegados, representando 68 organizações trabalhistas, de- 
cidem constituir a Confederação Brasileira do Trabalho (CBT), "a limitação da jornada para mulheres e menores de 14 anos" era uma das principais conquistas por quê deveria lutar (Dulles, 1977).

Durante a eclosão do movimento grevista na cidade de São Paulo, em $1917^{1}$, que envolveu mais de 20 mil operários, foi constituído um Comitê de Defesa Operária, composto por líderes trabalhistas. Dentre as 11 reivindicações que compunham a lista que estava sendo negociada com os capitalistas, constavam a "abolição do trabalho noturno para as mulheres e menores de 18 anos; e abolição do trabalho nas fábricas para os menores de 14 anos" (Dulles, 1977, p. 54). Naquele mesmo ano, no Rio de Janeiro, os operários da companhia de tecidos América Fabril, em greve, além de outras reivindicações, solicitavam "escolas para as crianças" (p. 57). Em São Paulo, a limitação da jornada em oito horas e a proibição do trabalho dos menores de 14 anos foi conquistada posteriormente, em $1919^{2}$, face a novo movimento paredista dos operários (p. 74-77).

Como consequiência desses embates, observaram-se algumas reformas na legislação social, como foi o caso da Lei de Acidentes do Trabalho, de 1919. Contudo, somente no ano de 1927, depois de tramitar durante os governos de Epitácio Pessoa e Arthur Bernardes, foi promulgado por Washington Luis o Código de Menores, uma legislação que, no contexto de uma "regulamentação da infância em geral" (Abreu \& Martinez, 1997, p. 28), também buscava "organizar as formas de trabalho" (p. 28). O Código, assim como o Juízo de Menores do Rio de Janeiro, criado em 1923, de "filosofia higienista e correcional disciplinar", expressava a concepção de que os problemas pertinentes às crianças possuem uma especificidade jurídica. Ele definia a idade mínima de 14 anos para o trabalho, a jornada diária de 6 horas e a proibição do trabalho noturno.

Em 1930, quando Getúlio Vargas assume o poder, o trabalho passa a ser objeto de atenção particular do seu governo, recrudescendo a perspectiva de controle dos menores enquanto potenciais trabalhadores. Naquela conjuntura foi formulado um projeto político-ideológico que, de acordo com Alencar (1997), "[...] tendo como substrato central a valorização do trabalho, passava a constituir todas as dimensões da vida social dos trabalhadores passíveis de observação e intervenção. Tornava-se comum nesse contexto um projeto de inculcação ideológica e doutrinária para a criação do cidadão-trabalhador, tornado expresso [...] nos discursos do próprio Vargas, nos pronunciamentos de ministros e figuras vinculadas ao governo" (p. 104).

As políticas praticadas na época aprofundavam a distinção entre "criança" e "menor", sobrepondo ao conteúdo autoritário uma perspectiva ideológica, que oferecia as bases para o controle da juventude do país, ou seja, definia um campo de intervenção social que buscava integrar, disciplinar e tornar governáveis os membros das classes mais pobres. As crianças tinham suas necessidades de proteção da maternidade, educação, saúde a cargo do Departamento Nacional da Criança, enquanto os "menores", o estudo e a ação sobre seus desvios, era responsabilidade do Serviço de Assistência a Menores (SAM), criado em 1941 (Abreu \& Martinez, 1997).

Muito embora comprometido com a urbanização e o desenvolvimento do capitalismo no país, uma importante característica do governo getulista era a conciliação que operava entre os diferentes interesses dos capitalistas e dos trabalhadores, por um lado garantindo as condições de desenvolvimento do capital e por outro implementando um conjunto de leis protetivas aos demais. A despeito de tal política populista, seus interesses maiores justificavam a repressão à organização dos trabalhadores, de modo que estes eram obrigados a se submeter ao controle ideológico-político do governo.

Amortecido o poder de luta dos trabalhadores, o campo ficava livre para as ações dos capitalistas. Apesar da ênfase sobre a família do trabalhador, a legislação de combate ao trabalho de crianças sofreu modificações, conseguindo os industriais a eliminação da barreira que proibía o trabalho antes dos 14 anos. Somente em 1943, com a promulgação da Consolidação das Leis do Trabalho (CLT) e incorporação das prescrições do Código de Menores sobre o trabalho, ou seja, idade mínima de 14 anos, jornada diária de 6 horas e proibição do trabalho noturno, recuperam "os menores" uma parcela da dignidade perdida, pelo menos sob o ponto de vista legal.

\section{Conclusão}

Assim, na esteira das concepções portuguesas e inglesas sobre o trabalho, também no Brasil conforma-se uma ideologia que o reifica, encobrindo seu verdadeiro papel no processo de produção de valor. De uma maneira geral mostrado como dignificante, educador, por seu intermédio são operadas uma separação e discriminação entre as classes sociais, na medida em que àquelas menos privilegiadas na escala social destina-se o trabalho manual, considerado ignominioso pelas classes abastadas, as quais reivindicam o trabalho intelectual, de concepção das ações a serem desenvolvidas pelos demais trabalhadores. Essa discriminação também se configura na distinção entre os conceitos de menor e criança, e em propostas diferenciadas como a profissionalização e a repressão, para os primeiros, e os serviços essenciais como educação e saúde, para as crianças.

Por fim, na perspectiva de se construir propostas mais eficazes de combate ao trabalho infantil, a ação sobre esses aspectos subjetivos não poderá ser esquecida. Somente na medida em que se questionar a lógica que justifica o trabalho das crianças para os pais e para elas próprias, acredita- 
se, lograr-se-á maiores êxitos na perspectiva da erradicação do trabalho infantil. Nunca é demais lembrar, contudo, que, como fica claro no início deste estudo, o trabalho infantil não decorre, simplesmente, de uma falsa consciência do papel do trabalhona sociedade, como se estafalsa consciêncianãorepousasse sobre uma estrutura material que a constrói e alimenta.

\section{Referências}

Abreu, M. E., \& Martinez, A. F. (1997). Olhares sobre a criança no Brasil: perspectivas históricas. In I. Rizzini (Org.), Olhares sobre a criança no Brasil: séculos XIX e XX (pp. 19-37). Rio de Janeiro: USU/AMAIS.

Adorno, S. (1993). Criança: a lei e a cidadania. In I. Rizzini (Org.), A criança no Brasil hoje: desafio para o terceiro milênio. (pp. 101112). Rio de Janeiro: Santa Úrsula.

Alencar, M. M. T. de. (1997). A política da família no Estado Novo e a atuação do Serviço Social. Em Pauta, 11, 99-112.

Ariès, P. (1978). História social da criança e da família. Rio de Janeiro: Zahar.

Dulles, J. W. F. (1977). Anarquistas e comunistas no Brasil, 1900-1935. Rio de Janeiro: Nova Fronteira.

Faleiros, V. P. (1995). Infância e processo político no Brasil. In F. Pilotti \& I. Rizzini. (Orgs.), A arte de governar crianças: a história das políticas sociais, da legislação e da assistência a infância no Brasil (pp. 47-98). Rio de Janeiro: Iin/Amais/Santa Úrsula.
Faoro, R. (2000). Os donos do poder: formação do patronato político brasileiro (15 $5^{\mathrm{a}}$ ed.). São Paulo: Globo.

Foot, F. E., \& Leonardi, V. (1982). História da indústria e do trabalho no Brasil: das origens aos anos vinte. São Paulo: Global.

Holanda, S. B. de. (1984). Raízes do Brasil (18 $8^{\mathrm{a}}$ ed.). Rio de Janeiro: José Olympio.

Horn, P. (1994). Children's work and welfare, 1780-1890. Cambridge: Cambridge University Press.

Kramer, S. (1982). A política do pré-escolar no Brasil: a arte do disfarce. Rio de Janeiro: Achiamé.

Mészáros, I. (1995). Beyond capital (Towards a theory of transition). Londres: Merlin Press.

Patto, M. H. S. (2000). Mutações do cativeiro: escritos de psicologia e política. São Paulo: Hacker/Edusp.

Rizzini, I., Rizzini, I., \& Holanada, F. R. B. de. (1995). A força da infância não está no trabalho. Rio de Janeiro: USU.

Rizzini, I. (1993). A assistência à infância no Brasil: uma análise de sua construção. Rio de Janeiro: Santa Úrsula.

Rizzini, I.. (1997). Principais temas abordados pela literatura especializada sobre infância e adolescência: séculos XIX e XX. In I. Rizzini (Org.), Olhares sobre a criança no Brasil: séculos XIX e XX (pp. 39-77). Rio de Janeiro: USU/Amais.

Saes, D. (1985). A formação do estado burguês no Brasil (1888 - 1891) ( $2^{\mathrm{a}}$ ed.). Rio de Janeiro: Paz e Terra.

Weber, M. (1989). A ética protestante e o espirito do capitalismo (6-a ed.). São Paulo: Pioneira.

\section{Notas}

1 Em declaração desse ano de 1917, citado por Faleiros (1995, p. 62), afirmava Jorge Street, um importante capitalista da época que, “[...] tem nas fábricas que dirige cerca de trezentas crianças, "todas trabalham dez horas, como os adultos", argumenta que são os pais que aí desejam seus filhos, alegando que lhes dá trabalhos leves, considerando justo que se regulamente o trabalho infantil, mas "as medidas não podem ser exageradas" e não se pode pintar os industriais como carrascos. Diz ainda: "se a futura lei reduzir o trabalho pela metade assim também reduziremos o salário" e que "a oficina, com seus inconvenientes, é preferível à rua com todos os seus perigos", propondo a permissão ao trabalho a partir de onze anos, considerando "exagero pernicioso" a proibição do trabalho até os 14 anos [...]"

2 Nesse ano de 1919, de acordo com números apresentados por Faleiros (1995, p. 61), era de “[...] $50 \%$ a participação feminina na indústria têxtil e a do menor em 35\%, no Estado de São Paulo [...] os menores representam mais de 7\% no setor secundário. Não havia, em geral, redução da jornada para as crianças e seus salários eram mais baixos que o dos adultos [...] nas oficinas da Casa da Moeda 70\% das crianças e adolescentes haviam contraído [a tuberculose].

Herculano Ricardo Campos, doutor em Educação pela Universidade Federal do Rio Grande do Norte (UFRN), é professor do Departamento de Psicologia da UFRN. Endereço para correspondência: Av. Afonso Pena, 1199/206, Tirol, 59020-100, Natal, RN, Fone/fax: (84) 222-3035. E-mail: hercules@ufrnet.br.

Alex Reinecke de Alverga é estudante do Curso de graduação em Psicologia da UFRN e bolsista CNPq/PIBIC.E-mail: alverga@uol.com.br. 